\title{
Impact of the SARS-CoV-2 Pandemic on the Treatment and Care of Patients With Chronic Kidney Disease in Germany: Results of a Nationwide Survey
}

\section{Victor Walendy}

Universitatsklinikum Halle

\section{Matthias Girndt}

Universitatsklinikum Halle

Daniel Frederik Greinert ( $\nabla$ daniel.greinert@uk-halle.de )

University Hospital Halle (Saale) Department of Internal Medicine II Ernst-Grube-Str.40 06120 Halle (Saale) Germany https://orcid.org/0000-0001-6897-7115

\section{Research article}

Keywords: SARS-CoV-2, Verband Deutscher Nierenzentren (DN), Kuratorium für Dialyse und Nierentransplantation $(\mathrm{KfH})$

Posted Date: September 28th, 2020

DOI: https://doi.org/10.21203/rs.3.rs-66174/v1

License: (c) (1) This work is licensed under a Creative Commons Attribution 4.0 International License. Read Full License 


\section{Abstract}

Impact of the SARS-CoV-2 pandemic on the treatment and care of patients with chronic kidney disease in Germany: Results of a nationwide survey Background/Aims The SARS-CoV-2 pandemic is a major challenge for patients, healthcare professionals and populations worldwide. Many peculiarities arise in dealing with outpatient and inpatient dialysis patients, patients with chronic kidney disease, or kidney transplantation. We conducted this first nationwide survey in German dialysis facilities to map the situation in May 2020, to explore the feasibility of the hygiene recommendations, and to identify changes in non-dialysis CKD-patient treatment. Methods A cross-sectional voluntary online questionnaire survey with 65 items was distributed by email using the mailing list of the DGfN as the scientific association for Nephrology, the "Verband Deutscher Nierenzentren (DN)" as the association of German dialysis facilities in private practice, and the "Kuratorium für Dialyse und Nierentransplantation $(\mathrm{KfH})$ ", the largest nonprofit dialysis service provider in Germany. The target population was nephrologists in dialysis facilities. 382 participants took part in the survey. Results The majority of centers were able to treat SARS-CoV-2infected dialysis patients or had agreements with other centers to transfer these patients. Until mid-May $42 \%$ already treated SARS-CoV-2 infected dialysis Patients. Compliance with the hygiene recommendations is considered high among employees and patients. Nevertheless $18 \%$ of the facilities reported infected staff, which in $55 \%$ of the cases were presumably work-related. Changes in the area of deployment of employees who belong to the risk group pressurize personnel situation in the dialysis facilities, as well as sickness-related absences or quarantine orders by the health authorities.

Perspectively a majority expects economic losses (82\%), shortage of safety equipment (53\%) and staff (74\%), respectively. Conclusion The SARS-CoV-2 pandemic had a significant impact on the care of patients with chronic kidney disease, but there were no obvious deficits in care. This is probably due to the high degree of cooperation among dialysis provider and comprehensive recommendations of nephrologists societies.

\section{Introduction}

The SARS-CoV-2 pandemic is a major challenge for patients, healthcare professionals and populations worldwide. Many peculiarities arise in dealing with outpatient and inpatient dialysis patients, patients with chronic kidney disease, or kidney transplantation. These patients belong to risk groups for severe COVID-19 courses due to age, comorbidity or indispensable immunosuppressive treatment ${ }^{1}$.

Particular risks compared to other patient groups result from the regular three times weekly cohorted treatment of dialysis patients who are immunologically weakened by their underlying disease.

The increased risk of SARS-CoV-2-infection is accentuated by the fact, that dialysis patients need transportation to the dialysis facility. The majority of patients are regularly transported by qualified ambulances, taxis, or - for economic reasons - group transportation. 
During the current SARS-CoV-2 pandemic, the staff of dialysis facilities are also exposed to a high risk of SARS-CoV-2 infection due to the numerous and intense patient contacts. In addition, there is a high demand for materials, including protective equipment for the personnel-intensive dialysis treatment. Employees in dialysis facilities may also belong to risk groups for severe COVID-19 courses ${ }^{2}$.

To address the need for guidance in this situation, especially for dialysis patients, the German Society for Nephrology (DGfN) ${ }^{3}$ and the European Renal Association (ERA-EDTA) ${ }^{4}$ published specific guidelines for the prevention of infection and the handling of SARS-CoV-2-positive patients. They consider the experience of Italy, Spain, or France that were hit much harder by the pandemic than Germany. Further, general recommendations are given in Germany by the governmental public health body called the Robert Koch Institute (RKI).

We conducted this survey in German dialysis facilities to map the situation in May 2020 and to explore whether and how these recommendations can be implemented in reality.

Furthermore, we describe relevant changes in ambulatory treatment of non-dialysis CKD-patients.

\section{Methods}

We derived a questionnaire including 65 items from the recommendations of the COVID-19 working group of the DGfN ${ }^{3}$. Our survey was designed as a multicentre, non-interventional and descriptive crosssectional study. The questionnaire was distributed by email using the mailing list of the DGfN as the scientific association for Nephrology, the "Verband Deutscher Nierenzentren (DN)" as the association of German dialysis facilities in private practice, and the "Kuratorium für Dialyse und Nierentransplantation $(\mathrm{KfH})$ ", the largest non-profit dialysis service provider in Germany. This approach enabled us to reach virtually every dialysis facility in Germany.

The survey was conducted between 4th and 14th of May in 2020. All participants were kept anonymous. The population of interest in this study was practicing nephrologists in dialysis facilities in Germany. For this study approval by the Ethics Committee of the Faculty of Medicine of the Martin-Luther-University was granted.

We used an online questionnaire which was stored on a LimeSurvey-Server hosted by the Martin-LutherUniversity Halle-Wittenberg. Data protection and data security was guaranteed according to the German data protection guidelines (Datenschutz-Grundverordnung, DSGVO). The questionnaire included 65 items, split into 8 different parts (eSupplement).

\section{Statistics}

382 participants took part in the survey and 248 responded fully to the questionnaire. The missing data analysis of the incompletely answered questionnaires showed that most of the answers were missing in the section on immunosuppressed-and kidney transplant patients. Especially questions regarding COVID- 
19 infections in immunosuppressed-and kidney transplant patients resulted in higher numbers of missing data. We used multiple imputation to address missing data ${ }^{5}$. We used predictive mean matching for continuous and binary variables, for ordinal scaled variables polytomous logistic regression was used. We assumed missing at random (MAR) as the underlying missing data mechanism.

Statistical analysis and preparation of figures was performed using $\mathrm{R}^{6}$, for multiple imputation the MICEPackage $^{7}$ was used. Data analysis was carried out using descriptive statistics which are presented as absolute or relative frequencies. Since there were no preliminary studies on this topic and the statistical analyses are only of descriptive nature, we did not perform a dedicated power calculation. We calculated the relative response rate by dividing the absolute number of responses by the number of dialysis centres in Germany.

\section{Results}

\section{Participants}

A total of 382 persons responded to the questionnaire, we estimated the relative response rate at $52 \%$. $77.0 \%(n=294)$ of the participants were employed as medical directors, $16.2 \%(n=62)$ as employed nephrologists, $6.8 \%(n=26)$ were nurses.

Predominantly the participants were employed in ambulatory dialysis centers (84,0\%). $16,0 \%$ were treating patients in hospital institutions. Since some participants were active in both the outpatient and inpatient sector $(9.5 \%)$, there was an overlap.

Among the participants from outpatient dialysis facilities $63.4 \%$ were occupied in private dialysis centers, 28.8 \% by non-profit institutions and $7,9 \%$ by other institutions. According to the $\mathrm{DGFN}$, this distribution of

providers reflects the current outpatient care of dialysis patients ${ }^{8}$. The distribution of respondents among the German states corresponds to the respective density of dialysis centers according to the quality assurance report ${ }^{9}$. The size distribution of the dialysis facilities also reflects a representative picture of care $(16.8 \%$ of the centers treated $<50$ chronic dialysis patients, $30.9 \%$ treat between 50 and 100 patients, $52.4 \%$ treat $>100$ patients).

In mid-May 2020, $55.0 \%$ of those surveyed had already treated dialysis patients with a proven SARS-CoV2 infection. Furthermore, $23.8 \%$ of the participants stated that they had treated immunosuppressed patients with kidney disease and $8.9 \%$ kidney transplant patients with proven SARS-CoV-2 infection, respectively.

\section{Implementation of the hygiene recommendations}

The DGfN recommends the appointment of (at least) one employee per dialysis facility to gather special information about SARS-CoV-2 and making this information available to the team. This was implemented in $81.4 \%$ of the participating centers. In $90.3 \%$ of the facilities, the staff was trained how to 
handle patients infected with SARS-CoV-2. The majority of the centers assessed the level of information of the staff as being very good $(22.5 \%)$ or good $(51.8 \%)$. The compliance to follow the hygiene regulations was high ( $28.5 \%$ very good; $44.5 \%$ good).

The majority of the facilities assessed the level of information of their patients about hygienic precautions as very good (38.2\%) or good (47.9\%). Compliance with the hygiene requirements was regarded as high ( $9.9 \%$ very good; $48.4 \%$ good). Overall, only $17.8 \%$ reported less well or poor compliance. Patients were informed in $79.6 \%$ of cases by personal education, in $63.5 \%$ by postings and in $71.9 \%$ by handouts. Patients with fever or acute respiratory disease are urged to call the institution by phone before entering a dialysis facility so that the procedure can be coordinated and the remaining patients of the center can be protected. Nevertheless, in $59.7 \%$ of the facilities, the situation arose that a patient only reported such symptoms after entering the facility.

\section{Changes in dialysis care}

The DGfN guideline suggests that dialysis facilities plan in advance if they can treat SARS-CoV-2-infected dialysis patients themselves or transfer them to other centers. Only $18.1 \%$ of the responding facilities declined care for infected patients. The main reasons given were structural conditions of the buildings (4\%) and the insufficient availability of protective equipment or disinfectants (1\%). Nearly all centers that cannot treat SARS-CoV-2- positive patients made arrangements with other dialysis providers to ensure that patients can be treated if necessary.

In the pandemic situation, the DGfN advises against transporting patients in group transports. Group transports are one way to reduce the high travel costs of outpatient dialysis care. Figure 1 shows the impact of the pandemic on patient transport. The share of collective transports is clearly declining (Fig. 1a - Change in group transport). A side effect is the significant increase in the use of qualified patient transport during the pandemic (Fig. 1b-Medically qualified transport).

A large proportion of the facilities (52.4\%) carry out regular entrance checks (fever measurements) for patients; these are carried out randomly in $42.9 \%$ and completely in $57.1 \%$ respectively.

\section{Deployment of dialysis staff}

As many as $24.9 \%$ of the facilities reported infections among their employees, $35.3 \%$ of which were presumably work related.

There are no recommendations to carry out regular SARS-CoV-2 swabs on medical staff. Nevertheless, $8.9 \%$ of the facilities reported to rely on such swabs and $25.1 \%$ planned on implementing them. This is probably due to a particular concern for the health status of staff, as $49.2 \%$ of the centers have identified staff who have an increased risk of severe COVID-19 courses due to age or previous illnesses. In almost all cases this has led to a change in the daily work routine (Fig. 2 - Deployment of staff).

Figure 2 
If a shortage in staff occurs in critical infrastructure facilities (i.e. also dialysis facilities) the Robert Koch Institute allow that contact persons (with limited exposure risk) can proceed their work under strict hygienic conditions. Such a critical situation was identified by $25.1 \%$ of the reporting centers.

\section{Outpatient care for non-dialysis CKD-Patients and patients with kidney transplantation}

The presentation of patients in the nephrological outpatient clinics was generally significantly reduced, $80.9 \%$ of the facilities reported having reduced presentation frequencies. $61.8 \%$ of those surveyed stated that they offered a telephone or video consultation, $61.3 \%$ also prescribed medication without patient contact in the pandemic situation.

Almost all nephrological facilities treated immunosuppressed patients with renal insufficiency and patients after kidney transplantation. These patients are at risk of suffering a severe COVID-19 course due to the underlying disease and therapeutic immunosuppression. Most facilities have reacted to this with changes in care (Table 1- Change in care of immunosuppressed and kidney transplanted patients).

The ERA-EDTA has published recommendations on how to deal with immunosuppression in kidney transplant patients, but only $29 \%$ of the respondents who treated SARS-CoV-2-infected patients with a kidney transplant followed these recommendations. $36 \%$ were unaware of these recommendations.

\section{Perspective}

In mid-May, scepticism prevailed with regard to the further development in the care of patients with chronic kidney disease. Future staff shortages were considered very likely by $21.5 \%$ and likely by $44.0 \%$, respectively, of those surveyed. Lack of protective equipment was feared by $18.1 \%$ (very likely) and $34.6 \%$ (likely), respectively.

Finally, the participants were asked to give their assessment of whether the SARS-CoV-2 pandemic would have economic consequences for their institution (Fig. 3 - Perspective economic consequences).

\section{Discussion}

The treatment of chronic dialysis patients always requires high demands on hygiene for several reasons. Renal insufficiency leads to immunodeficiency and increased susceptibility to infection ${ }^{10,11}$. Patients are regularly treated in dialysis centers in a coherent manner three times weekly while they are in a nonmedical and therefore not hygienically controllable environment between treatments. In addition, many patients are transported to and from treatment-facilities by taxi, group transport or qualified ambulance services. This is a complex situation even when dealing with multi-resistant bacteria ${ }^{12}$, and it became a challenge in the context of the pandemic.

Experience from Italy ${ }^{13}$ and Spain ${ }^{14}$ indicates that dialysis patients have a particularly high mortality risk (approx. 30\%) when infected with SARS-CoV-2. The German Society for Nephrology (DGfN) therefore 
made organizational and hygienic recommendations ${ }^{3}$ at an early stage to protect this vulnerable patient group. Persons under therapeutic immunosuppression are also at risk, including patients with a kidney transplant. Recommendations for dealing with immunosuppression were formulated by the European Renal Association ${ }^{4}$.

This survey shows that dialysis facilities in Germany felt well informed and prepared, and both staff and patients followed the hygiene measures well, according to the respondents. Thus, $81.9 \%$ of the facilities also felt able to continue treatment of dialysis patients when they got infected with SARS-CoV-2, although the separation or cohorting places high demands on premises and staff. Facilities that were unable to do this have made arrangements with other providers to ensure that patients are cared for in all cases. Dialysis care is secured - also through cooperation across the boundaries of different providers.

The pandemic has brought significant changes in patient transport management. Medically necessary journeys to dialysis are fully covered by the health care insurance system in Germany, accounting for up to $20 \%$ of the total costs of renal replacement therapy. For this reason, collective transports are often organized - unless there are medical reasons not to do so. In the pandemic situation group transports of dialysis patients in one vehicle are not recommended by the DGfN. The changeover to individual transport has taken place on a large scale, although not nationwide. This is associated with relevant additional costs, as is the expansion of the use of qualified patient transport. It will be challenging to find a balance between infection prevention and economy in the further course of the pandemic.

The deployment of staff in the dialysis center, especially the deployment of employees who belong to the risk group for severe COVID-19 courses, is also a burden for the facilities. According to the participating facilities, work related SARS-CoV-2 infections have already occurred. This constellation met the requirements for recognition as an occupational disease ${ }^{15}$.

Changes in the area of deployment of employees who belong to the risk group pressurize personnel situation in the dialysis facilities, as well as sickness-related absences or quarantine orders by the health authorities. Against the background of the highly specialized qualification requirements in dialysis care, it is remarkable that so far only $16 \%$ of the facilities have experienced severe staff shortage, which under a rule of exception allows the continued use of contact persons of COVID-19 patients in patient care ${ }^{16}$.

As in all areas of outpatient care, patient contacts have been significantly reduced in recent weeks. Patients under therapeutic immunosuppression, e.g. for glomerulonephritis or after kidney transplantation, are particularly at risk of infection. It is very comprehensible that the frequency of presentation of these patients in the outpatient clinics was deliberately reduced, but this is not without risks. Especially in the early stages of therapy, frequent corrections of the dosage of immunosuppressive drugs are necessary. After organ transplantation, some immunosuppressive drugs are adjusted according to plasma levels. 
Immunosuppression is not reduced prophylactically after kidney transplantation. This procedure is in accordance with the recommendations of the ERA-EDTA ${ }^{4}$, according to which a reduction of immunosuppression in COVID-19 infection, graded according to the severity of the disease, is planned, but not as a prophylactic measure.

This survey was the first nationwide survey and analysis among nephrologist about the SARS-CoV-2 epidemic in Germany.

Through the different involved organisations ( $\mathrm{DGfN}, \mathrm{DN}, \mathrm{KfH}$ ) we could almost reach every nephrologist in Germany. This resulted in a good response rate, especially among medical directors who in general represent a dialysis facility and primarily influence the implementation of hygiene recommendation and care of dialysis and CKD-non-dialysis patients.

The distribution of provider (private, non-profit and others) in our survey reflects the current outpatient care of dialysis patients in Germany.

With our approach we achieved a good representativeness of dialysis facilities in Germany. General limitations of non-interventional and descriptive cross-sectional studies also apply to our survey.

In summary, the SARS-CoV-2 pandemic already has had a significant impact on the care of patients with chronic kidney disease in Germany, although infection numbers were lower than in several neighbouring countries. However, evident deficits in the treatment are not obvious.

This is due to the high degree of willingness to cooperate across different dialysis providers and the comprehensive formulation of practical recommendations by the professional associations.

\section{Abbreviations}

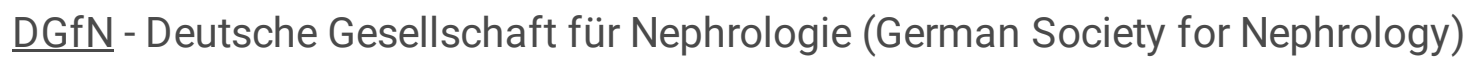

ERA-EDTA - European Renal Association - European Dialysis and Transplant Association

$\underline{\text { RKI }}$ - Robert Koch Institut (German governmental public health body)

$\underline{\text { CKD }}$ - Chronic Kidney Disease

DN- Verband Deutscher Nierenzentren (Association of German dialysis facilities in private practice)

$\underline{\mathrm{KfH}}$ - Kuratorium für Dialyse und Nierentransplantation (non-profit dialysis service provider in Germany)

\section{Declarations}

\section{Ethics Approval and consent to participate}


- There was an Ethic approval of this study from the "Ethik-Kommission der Medizinischen Fakultät der Martin-Luther-Universität Halle-Wittenberg" (Ethic commission of the medical faculty of the Martin-Luther-University Halle-Wittenberg). The reference number is 2020-064

- The Ethic Comission stated that they have no concerns regarding this study.

\section{Consent for publication}

- The survey was anonymous and didn't include any individual person's data in any form

\section{Availability of data and materials}

- The datasets used and/or analysed during the current study are available from the corresponding author on reasonable request

\section{Competing interests}

- None of the authors receive any payment or services from a third party for any aspect of the submitted work.

- A Non-Financial competing interest could be that Prof. Girndt is Member of the Commission for Hygiene and Infection Prevention in the German Society of Nephrology and Member of the Board of the German Society for Applied Hygiene in Dialysis

- Daniel Greinert and Dr. V. Walendy don't receive any funding, grants fee

- Dr. Girndt reports personal fees from Amgen, personal fees from Astellas, personal fees from Bayer Vital , grants and personal fees from Daiichi Sankyo, personal fees from Hexal, personal fees from Sanofi, personal fees from Vifor, outside the submitted work; and Commission for Hygiene and Infection Prevention, German Society of Nephrology

\section{Funding}

No funding was obtained for this study.

\section{Author contribution to the manuscript:}

DG, VG and MG conceived, designed and directed the study.

$D G, V G$ and $M G$ drafted and revised the manuscript.

DG and VG performed statistical work and contentual review of survey responses.

All other co-authors helped to develop and disseminate the survey. All authors approved the final manuscript and contributed critical revisions to its intellectual content 
Acknowledgements

Not applicable

\section{References}

\section{Bibliography}

1. Girndt M. Niereninsuffızienz und Infektionsanfälligkeit. Der Nephrol. [Internet]. 2020;15:268-271. Available from: https://doi.org/10.1007/s11560-020-00438-2

2. Nguyen LH, Drew DA, Joshi AD, Guo C-G, Ma W, Mehta RS, et al. Risk of COVID-19 among frontline healthcare workers and the general community: a prospective cohort study. medRxiv [Internet]. 2020;2020.04.29.20084111. Available from: http://medrxiv.org/content/early/2020/05/25/2020.04.29.20084111.abstract

3. DGfN. Verdacht auf oder Nachweis von SARS-CoV-2 Infektionen bei Dialysepatienten (Stand 07.04.2020) [Internet]. Available from: https://www.dgfn.eu/stellungnahmen-details/verdacht-aufoder-nachweis-von-sars-cov-2-infektionen-bei-dialysepatienten.html

4. ERA-EDTA. European Renal Association - European Dialysis and Transplantation Association: ERAEDTA Information for Nephrologists and other professionals on Prevention and Treatment of COVID19 Infections in Kidney Patients, [Internet]. Available from: https://www.era-edta.org/en/covid-19news-and-information/

5. Pessenda LCR, Lisi CS, Gouveia SEM. Multiple Imputation for Nonresponse in Surveys [Internet]. Hoboken, NJ, USA: John Wiley \& Sons, Inc.; 1987 [cited 2020 Jul 12]. Available from: http://doi.wiley.com/10.1002/9780470316696

6. Team RC. R: A language and environment for statistical computing [Internet]. 2020;Available from: www.r-project.org

7. van Buuren S, Groothuis-Oudshoorn K. mice: Multivariate imputation by chained equations in R. J. Stat. Softw. [Internet]. 2011 [cited 2020 Jul 13];45:1-67. Available from: https://www.jstatsoft.org/index.php/jss/article/view/v045i03/v45i03.pdf

8. DGfN. Deutsche Gesellschaft für Nephrologie: Stellungnahme der DGfN zu den industriellen Dialyseanbietern, 2017 [Internet]. Available from: https://www.dgfn.eu/stellungnahmendetails/stellungnahme-der-dgfn-zu-den-industriellen-dialyseanbietern.html

9. Medical Netcare GmbH: Jahresbericht 2017 zur Qualität in der Dialyse, 2018 [Internet]. Available from: https://www.g-ba.de/downloads/39-261-3487/2018-09-20_QSD-RL_MNC-Jahresbericht2017.pdf

10. Dalrymple LS, Mu Y, Nguyen D V, Romano PS, Chertow GM, Grimes B, et al. Risk Factors for InfectionRelated Hospitalization in In-Center Hemodialysis. Clin. J. Am. Soc. Nephrol. [Internet]. 2015;10:2170-2180. Available from: https://pubmed.ncbi.nlm.nih.gov/26567370 
11. Vijayan A, Boyce JM. 100\% Use of Infection Control Procedures in Hemodialysis Facilities. Clin. J. Am. Soc. Nephrol. [Internet]. 2018;13:671 LP - 673. Available from: http://cjasn.asnjournals.org/content/13/4/671.abstract

12. DGfN. Deutsche Gesellschaft für Nephrologie: Leitlinie zu Infektionsprävention und Hygiene 2019 als Ergänzung zum Dialysestandard, 2020 [Internet]. Available from: https://www.dgfn.eu/dialysestandard.html?file=files/content/leitlinien/hygieneleitlinie/20200127_LL-Hygiene-Einzelseiten.pdf

13. Alberici F, Delbarba E, Manenti C, Econimo L, Valerio F, Pola A, et al. Management Of Patients On Dialysis And With Kidney Transplant During SARS-COV-2 (COVID-19) Pandemic In Brescia, Italy. Kidney Int. reports [Internet]. 2020;Available from: http://europepmc.org/abstract/MED/32292866

14. Goicoechea M, Sánchez Cámara LA, Macías N, Muñoz de Morales A, Rojas ÁG, Bascuñana A, et al. COVID-19: clinical course and outcomes of 36 hemodialysis patients in Spain. Kidney Int. [Internet]. 2020;98:27-34. Available from: https://pubmed.ncbi.nlm.nih.gov/32437770

15. Deutsche Gesetzliche Unfallversicherung e.V.: COVID-19 als Berufskrankheit - Informationen für Beschäftigte im Gesundheitswesen, 2020 [Internet]. Available from: https://publikationen.dguv.de/widgets/pdf/download/article/3854

16. Robert-Koch-Institut: Optionen zum Management von Kontaktpersonen unter Personal der kritischen Infrastruktur bei Personalmangel, 2020 [Internet]. Available from:

https://www.rki.de/DE/Content/InfAZ/N/Neuartiges_Coronavirus/Personal_Kritls.html

\section{Tables}

Due to technical limitations, table 1 is only available as a download in the Supplemental Files section.

\section{Figures}
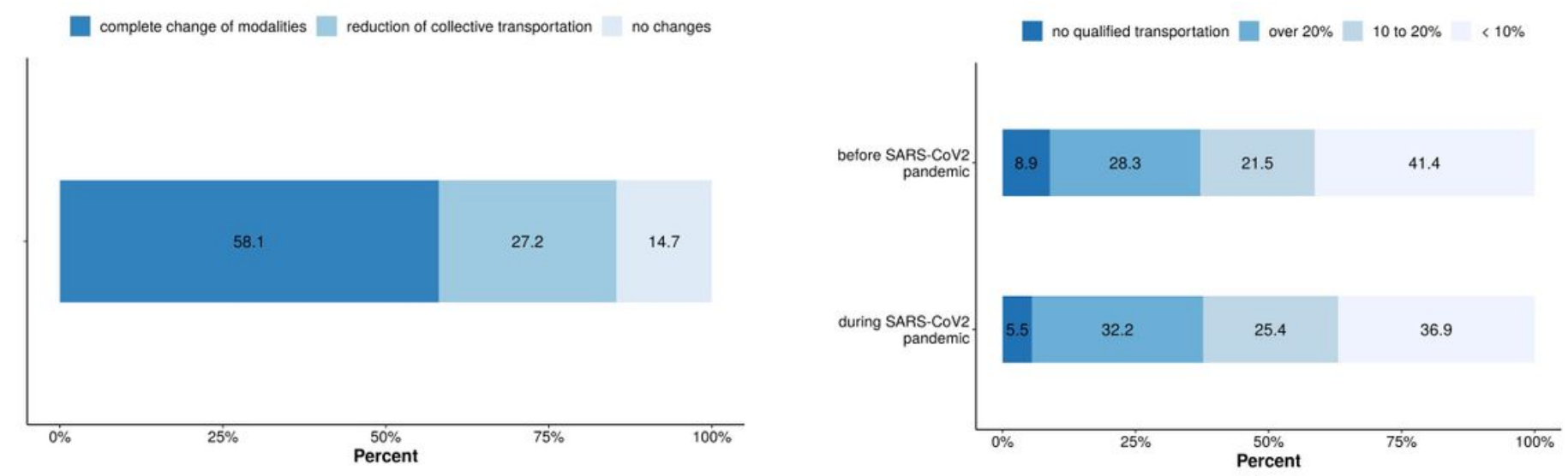

\section{Figure 1}

1a. Change in group transport $1 \mathrm{~b}$. The use of medically qualified transport 


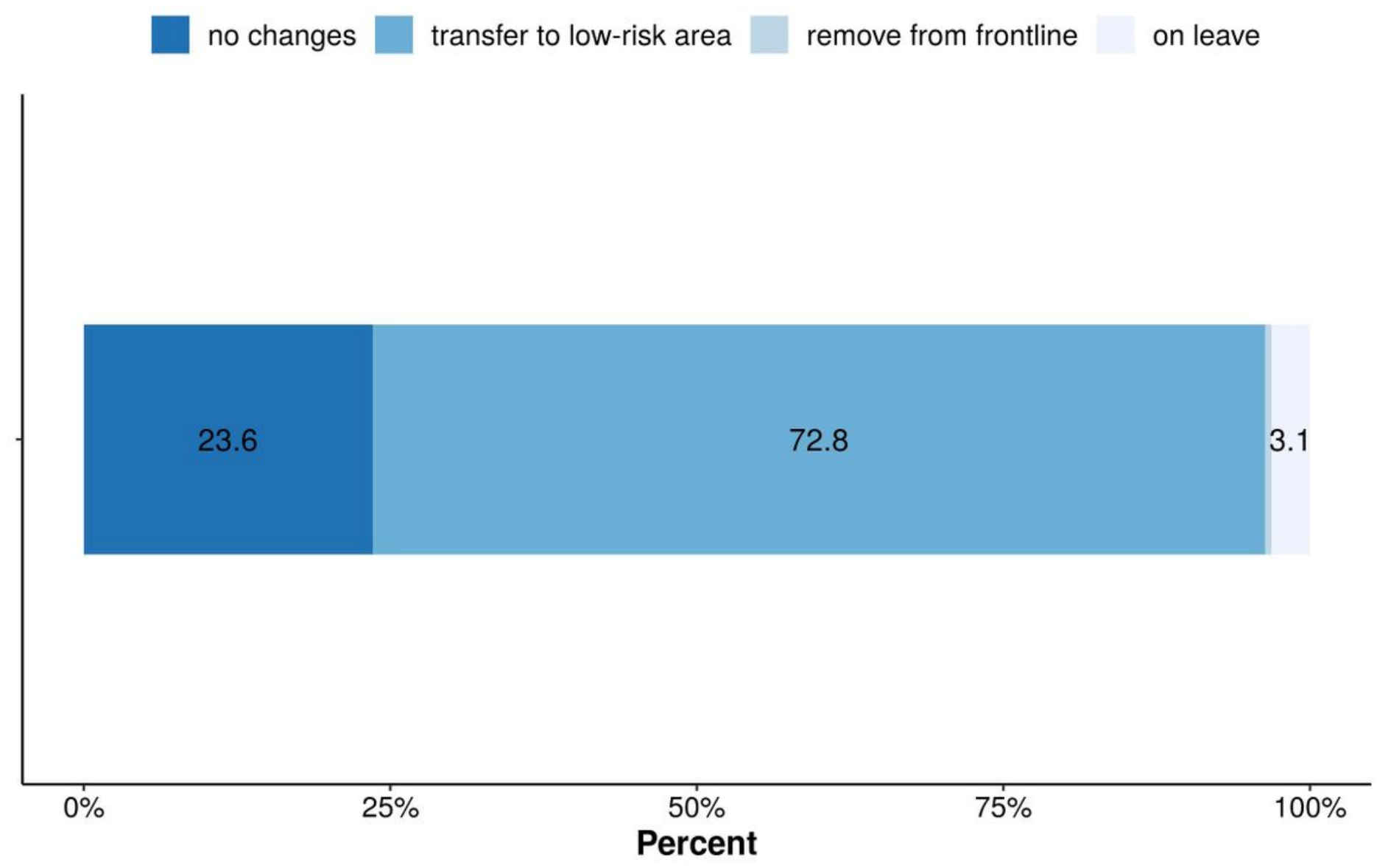

Figure 2

Deployment of staff 


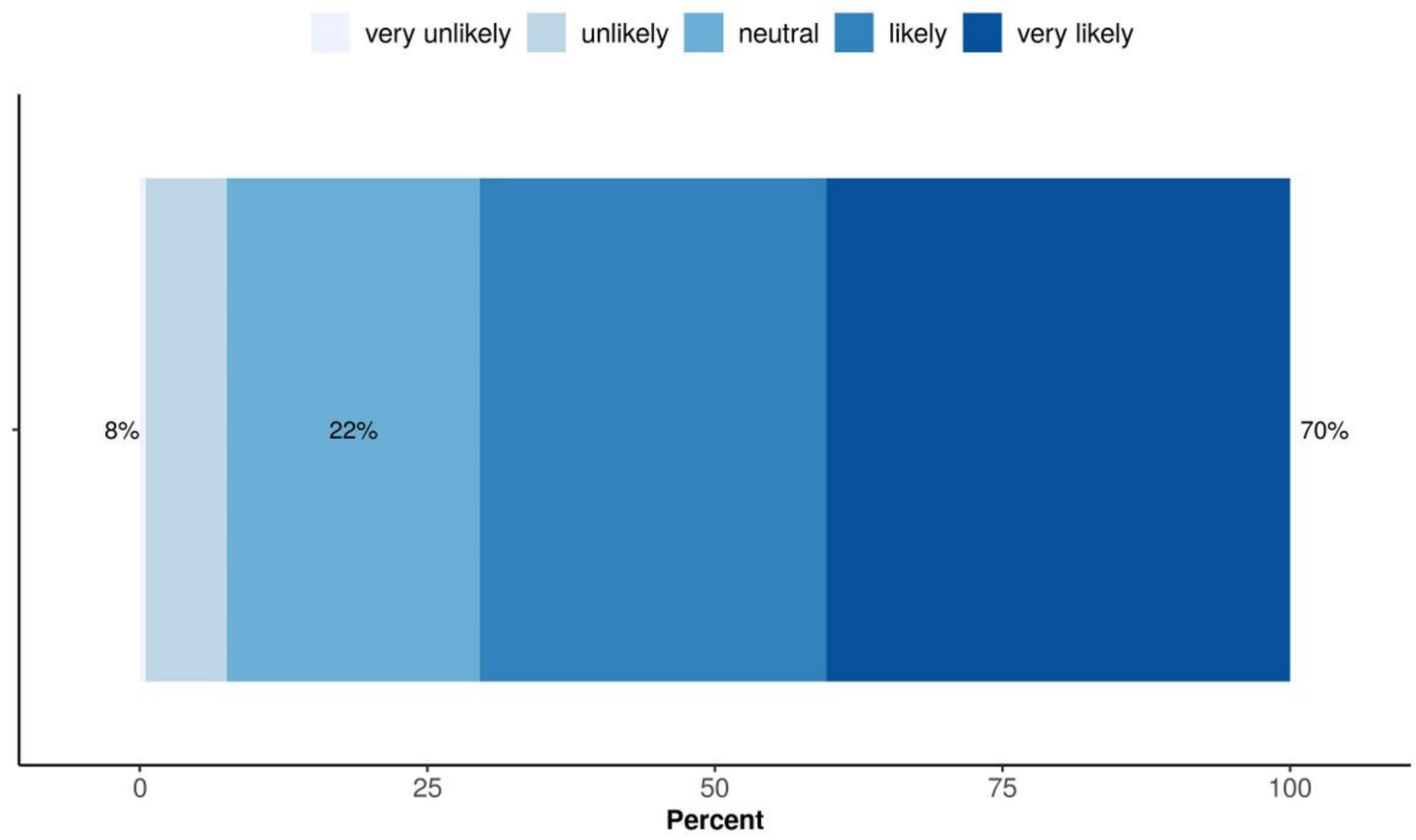

Figure 3

Perspective economic consequences

\section{Supplementary Files}

This is a list of supplementary files associated with this preprint. Click to download.

- Table1Changeincareofimmunosuandkidneytransp.pati..xlsx

- STROBEchecklistcrosssectional1.doc

- Questionnaire.docx 